\title{
SHADE MATCH OF CAD/CAM LITHIUM SILICATE ALL-CERAMIC RESTORATIONS: EFFECT OF CERAMIC THICKNESS AND NON- TOOTH COLORED FOUNDATION
}

\author{
Samah Saker *
}

\begin{abstract}
Statement of problem: Assessment of lithium silicate ceramics as regard to its thickness variances need evaluation with regard to color match to shade guide.

Purpose: This study aimed to investigate the effect of ceramic thickness and foundation restoration on color production of lithium silicate glass- ceramics.

Material and Methods: A total of 60 rectangular plate slices disks of shade A1 were prepared from CAD/ CAM generated all-ceramic materials IPS e.max CAD (EM) and Vita suprinity blocks(ZLS), with different thickness ( $1 \mathrm{~mm}, 1.5 \mathrm{~mm}$ and $2 \mathrm{~mm}$ ). The color of ceramic specimens before and after bonding to foundation blocks were measured using a reflectance spectrophotometer and CIE L*a*b* (Commission Internationale de L'Eclairage) color system were used for calculation of color parameter. The collected data were statistically analyzed using two-way ANOVA and the Tukey HSD test $(\alpha=.05)$.

Results: The 2-way ANOVA showed that the ceramic material composition $(\mathrm{P}<.05)$, ceramic thickness $(\mathrm{P}<.05)$ and tooth foundation all significantly affected $\Delta \mathrm{E}$ values $(\mathrm{P}<.05)$.

Conclusions: Reinforcement of CAD/CAM lithia silicate glass-ceramics by zirconia decreases the color match. Acceptance level between the two tested ceramic materials and thickness varied. At all evaluated thicknesses before bonding to foundation blocks, EM presented higher shade matching compared to ZLS. The effect of non tooth colored foundation can be overcome by increasing the thickness of fabricated restoration to enhance color production.
\end{abstract}

KEY WORDS: Lithium silicate ceramic, glass-ceramics, color, ceramic thickness.

*Assistant Professor, Fixed Prosthodontics Department, Faculty of Dentistry, Mansoura University, Mansoura, Egypt. 


\section{INTRODUCTION}

Creating a lifelike appearance in a restoration is certainly one of the most complex, challenging and controversial tasks in dentistry. Because esthetics has become increasingly important in dentistry, all ceramic restorations have been introduced to circumvent drawbacks caused by aesthetic limitations of metal-ceramic restorations. ${ }^{1}$

All-ceramic restorations may be fabricated using varieties of all-ceramic materials and fabrication techniques that have been introduced to the dental market. CAD/CAM technology has been introduced as an alternative for the traditional manufacturing processes. ${ }^{2-7}$

Lithium disilicate-reinforced glass-ceramics have generated considerable interest for fabrication of indirect restorations ranging from veneers to multiple-unit posterior fixed dental prostheses (FDPs) as well as to dental implant restorations as a result of the material's appropriate strength properties $(350-450 \mathrm{MPa})$, and restorations with good esthetic properties. ${ }^{6-9}$ Recently, VITA company (VITA Zahnfabrik, Bad Säckingen, Germany) has introduced new all ceramic material into dental market, Vita suprinity. Vita Suprinity, zirconium dioxide reinforced lithium silicate ceramic( ZLS) with especially fine-grained and homogeneous structure that was introduced under the argument that the addition of zirconia (from $8 \%$ to $12 \%$ per weight), could act as a crystal phase that can reinforce the material with the intention of improving fracture resistance through crack interruption. The lunching of the material into dental markets represents an attempt to unite the esthetic properties of the glassceramics in a monolithic restoration with resistance properties of polycrystalline ceramics.

Several factors were recorded as it could influence the capability of a ceramic system to reproduce an acceptable match with corresponding shade guides. ${ }^{15-20}$ The type of ceramics used , condensation techniques, batches, dentin thickness, firing temperatures, and number of porcelain firings, and thickness all participate to remarkable differences between the final shade of dental ceramics and their respective shade tabs. ${ }^{21-34}$

Tooth color is the result of optical interaction of light with enamel and dentin. The main optical parameters of enamel and dentin are brightness, hue and saturation and are often referred to as the single concept of chroma. ${ }^{10-14}$ Although allceramic systems used mainly to improve the color of the restorations, an ideal color result cannot be ensured. The color of the abutment tooth is mainly responsible for its color. Translucent ceramics allow light to enter and scatter, with the resultant, the underlying tooth substrates has a critical influence over the produced color. ${ }^{27}$

Restoration of endodontically treated teeth with different post and core systems, combined with all ceramic restorations might result in discoloration and shadowing, especially in the cervical part of the restorations and to overcome this unfavorable impact, such factors should be considered.

This investigation aimed to estimate the effect of different ceramic thicknesses (1,1,5 and 2mm) and non-tooth-colored foundation restoration on the shade matching of CAD/CAM zirconia reinforced lithium silicate glass-ceramics compared to lithium disilicate glass-ceramics. The null hypothesis was that $\mathrm{CAD} / \mathrm{CAM}$ lithium silicate glass-ceramics color would not be affected by either ceramic thickness or foundation restoration compared to lithium disilicate glass-ceramics.

\section{MATERIALS AND METHODS}

\section{Specimen preparation}

A total of 60 rectangular plate slices at thicknesses of 1, 1.5 and $2 \mathrm{~mm}$ were prepared from Lithium disilicate glass ceramic (EM, IPS e.max CAD; IvoclarVivadent) and zirconium dioxide reinforced lithium silicate ceramics (ZLS, Suprinity;Vita Zahnfabrik) blocks (Shade A1) in precrystalline stage using a water cooled, 
slow-speed diamond saw (Isomet, Buehler Ltd., Lake Bluff, IL). Crystallization of ceramic blocks was performed following manufacturers' instructions. The color-measuring surfaces of the specimens were finished flat with wet \#400, \# 800 and \#1200 grit silicon carbide paper. The final thickness of each specimen was verified as 1, 1.5 and $2 \mathrm{~mm}$ $( \pm 30 \mathrm{~mm})$ with digital callipers (Electronic Digital Caliper, Shan, China) and the specimens were cleaned ultrasonically in distilled water for $10 \mathrm{~min}$.

\section{Fabrication of non-tooth- colored foundation}

A foundation block was made by investing a $12 \times 14 \times 2-\mathrm{mm}$ acrylic resin pattern (Duralay; Reliance Dental) and was cast in base metal alloy (Durabond, Road that, CA, USA) with an induction casting machine following the manufacturer's instructions. The bonded surface of each foundation block was airborne-particle-abrasion using 100- $\mu \mathrm{m}$ Al2O3 (Korox, Bego, Bremen, Germany). To eliminate any surface contaminations, the foundation blocks were ultrasonically cleaned in distilled water (Healthsonics, Livermore, USA) for $10 \mathrm{~min}$ and air dried.

\section{Color measurement of ceramic specimens before bonding to foundation blocks}

For color evaluation; a computer-controlled reflectance spectrophotometer was conducted (UV3101PC; Shimadzu, Japan) with an integrating sphere attachment, illuminant D-65, range between 360 and $720 \mathrm{~nm}$, and viewing angle of $10^{\circ}$. Color coordinates, $\mathrm{L}^{*}$ characterizes lightness, $\mathrm{a}^{*}$ characterizes red-green chromaticity index and $\mathrm{b}^{*}$ characterizes yellow-blue chromaticity index, were determined from the transmittance and reflectance data using a computer software (X-rite; $\mathrm{GmbH}$ Optronic, Berlin, Germany).

\section{Bonding of ceramics disks to foundation blocks}

Before cementation, the bonded ceramic surfaces were treated with $9.6 \%$ hydrofluoric acid
(Porcelain etch, Pulpdent, Watertown, USA) for 20 seconds, rinsed with water and air dried. Ceramic primer (Monobond S; Ivoclar Vivadent) was applied for 60 seconds and air dried. The ceramic specimens were luted to the $\mathrm{Ni}-\mathrm{Cr}$ foundation blocks by using opaque white resin cement (Nexus NX3; Kerr Corporation). After removal of the excess resin cement, the specimens were photo-polymerized from each direction for $40 \mathrm{~s}$ and the specimens were kept under constant axial force until complete setting of the cement.

\section{Color measurement of ceramic specimens after bonding to foundation blocks}

The color coordinates $\left(\mathrm{L}^{*}, \mathrm{a}^{*}\right.$ and $\left.\mathrm{b}^{*}\right)$ of the ceramic specimens after bonding were accomplished following the same protocol as described previously. The $\Delta \mathrm{E}$ between different tested groups was calculated using the recorded $\mathrm{L}^{*}, \mathrm{a}^{*}$ and $\mathrm{b}^{*}$ values by using the color difference formula:

$$
\Delta \mathrm{E}=\sqrt{\left(\Delta \mathrm{L}^{*}\right)^{2}+\left(\Delta \mathrm{a}^{*}\right)^{2}+\left(\Delta \mathrm{b}^{*}\right)^{2}}
$$

Where:

$\Delta \mathrm{E}$ represent the total color difference, $\Delta \mathrm{L}^{*}$, $\Delta \mathrm{a}^{*}$ and $\Delta \mathrm{b}^{*}$ represent the difference of $\mathrm{L}^{*}, \mathrm{a}^{*}$ and $\mathrm{b}^{*}$ before and after bonding to substrate.

Measurement of the shade guide color properties

Shade A1 tab of the shade guide (chromascop, Ivoclar Vivadent), were used. The measurements of color properties were made using the same condition as described previously. The middle third part was used for color measurements. $\mathrm{L}^{*}, \mathrm{a}^{*}$ and $\mathrm{b}^{*}$ color coordinates of the tab was measured three times and the average was calculated.

\section{Statistical analysis}

The results of testing were statistical analyzed with statistical software (SPSS 20.0, SPSS Inc, Chicago, IL). Levene test was used to test for the 
data homogeneity. Two-way analysis of variance (ANOVA)) was used to analyze the data for significant differences in shade match recorded for the tested groups at the significance level of 0.05 , followed by the Tukey HSD post hoc test at a $95 \%$ confidence level for multiple comparisons.

\section{RESULTS}

The mean color coordinates $\left(\mathrm{L}^{*}\right),(* \mathrm{a})$, and $(* \mathrm{~b})$ values of all test groups before and after bonding to non-tooth-colored foundation and the color values of the A1 shade tab are presented in Table I.

TABLE (I) Means and standard deviations of the $\mathrm{L}^{*}, \mathrm{a}^{*}$, and $\mathrm{b}^{*}$ values of EM, ZLS and the scale before foundation block bonding. Significant difference $(\mathrm{P} \leq .05)$ was found among groups marked by different letters (a, b, c,.) while no significant difference was found among groups marked by similar letters.

\begin{tabular}{|c|c|c|c|c|}
\hline Group & & $\mathrm{L}^{*}$ & $\mathrm{a}^{*}$ & $\mathrm{~b}^{*}$ \\
\hline \multirow{3}{*}{$\mathrm{EM}$} & $\mathrm{C} 1$ & $73.8 \pm 2.7^{\mathrm{a}}$ & $.16 \pm 1.5^{\mathrm{A}}$ & $11 \pm 3.1^{\mathrm{F}}$ \\
\cline { 2 - 5 } & $\mathrm{C} 2$ & $73.0 \pm 3.3^{\mathrm{a}}$ & $-.48 \pm .8^{\mathrm{B}}$ & $10.7 \pm 2.8^{\mathrm{F}}$ \\
\cline { 2 - 5 } & $\mathrm{C} 3$ & $72.8 \pm 3.8^{\mathrm{a}}$ & $-.06 \pm 1.5^{\mathrm{C}}$ & $9.9 \pm 2.2^{\mathrm{F}}$ \\
\hline \multirow{3}{*}{ ZLS } & $\mathrm{C} 2$ & $72.2 \pm 2.4^{\mathrm{a}}$ & $.68 \pm 1.7^{\mathrm{D}}$ & $11.6 \pm 2.8^{\mathrm{F}}$ \\
\cline { 2 - 5 } & $69.6 \pm 2.2^{\mathrm{a}}$ & $1.8 \pm 1.2^{\mathrm{E}}$ & $11.4 \pm 1.3^{\mathrm{F}}$ \\
\cline { 2 - 5 } & $\mathrm{C} 3$ & $69.4 \pm 3.3^{\mathrm{a}}$ & $1.6 \pm 2.0^{\mathrm{E}}$ & $11.6 \pm 2.7^{\mathrm{F}}$ \\
\hline \multicolumn{2}{|c}{ Scale } & $73.5^{\mathrm{a}}$ & $0.8^{\mathrm{D}}$ & $10.8^{\mathrm{F}}$ \\
\hline
\end{tabular}

Before bonding to foundation blocks, there was no significant difference between the $\mathrm{L}^{*}$ value of the shade guide, EM and ZLS regardless the thickness of the ceramic specimens. (P>.05). However, EM showed the higher $\mathrm{L}^{*}$ values compared to ZLS group, regardless the thickness of the ceramic specimen and the difference were statistically insignificant.
The mean values of DE differed significantly among the 3 ceramic thickness groups $(1.0 \mathrm{~mm}$, $1.5 \mathrm{~mm}, 2.0 \mathrm{~mm}$ ) (Table II).

TABLE (II) Means and standard deviations of the $\mathrm{L}^{*}$, $\mathrm{a}^{*}, \mathrm{~b}^{*}$ and $\Delta \mathrm{E}$ values of EM and ZLS after bonding to foundation block. Significant difference $(\mathrm{P} \leq .05)$ was found among groups marked by different letters (a,b,c,.) while no significant difference was found among groups marked by similar letters.

\begin{tabular}{|c|c|c|c|c|c|}
\hline \multirow{2}{*}{ Group } & & $\mathrm{L}^{*}$ & $\mathrm{a}^{*}$ & $\mathrm{~b}^{*}$ & $\Delta \mathrm{E}$ \\
\hline \multirow{3}{*}{ EM } & $\mathrm{C} 1$ & $70.6 \pm 1.1^{\mathrm{c}}$ & $1.12 \pm 0.7^{\mathrm{C}}$ & $13.0 \pm 0.9^{\mathrm{E}}$ & $2.7 \pm 0.5^{\mathrm{Y}}$ \\
\cline { 2 - 6 } & $\mathrm{C} 2$ & $70.6 \pm 1.3^{\mathrm{c}}$ & $-0.81 \pm 1.0^{\mathrm{C}}$ & $12.7 \pm 0.9^{\mathrm{E}}$ & $2.1 \pm 0.1^{\mathrm{Y}}$ \\
\cline { 2 - 6 } & $\mathrm{C} 3$ & $66.2 \pm 1.5^{\mathrm{d}}$ & $-2.3 \pm 1.2^{\mathrm{D}}$ & $11.8 \pm 1.0^{\mathrm{F}}$ & $1.1 \pm 0.7^{\mathrm{y}}$ \\
\hline \multirow{3}{*}{ ZLS } & $\mathrm{C} 2$ & $70.4 \pm 2.3^{\mathrm{c}}$ & $1.3 \pm 1.2^{\mathrm{C}}$ & $12.2 \pm 1.2^{\mathrm{E}}$ & $2.4 \pm 0.8^{\mathrm{Y}}$ \\
\cline { 2 - 6 } & $67.3 \pm 1.4^{\mathrm{d}}$ & $2.83 \pm 0.25^{\mathrm{D}}$ & $11.3 \pm 1.3^{\mathrm{F}}$ & $0.8 \pm 0.6^{\mathrm{y}}$ \\
\cline { 2 - 6 } & $\mathrm{C} 3$ & $67.2 \pm 1.1^{\mathrm{d}}$ & $2.85 \pm 0.15^{\mathrm{D}}$ & $11.1 \pm 0.9^{\mathrm{F}}$ & $0.7 \pm 0.2^{\mathrm{y}}$ \\
\hline
\end{tabular}

Two-way ANOVA indicated significant difference $(\mathrm{P}<.001)$ between $1 \mathrm{~mm}$ thickness compared to $1.5 \mathrm{~mm}$ and $2 \mathrm{~mm}$ thickness of ceramic disks used in this study when the lightness parameter $\left(\mathrm{L}^{*}\right)$ was evaluated for of the bonded ceramic-foundation combinations of ZL specimens. While EM specimens, showed significant difference $(\mathrm{P}<.001)$ between $2 \mathrm{~mm}$ compared to $1 \mathrm{~mm}$ and $1.5 \mathrm{~mm}$ ceramic thicknesses. Similarly, a significant difference $(\mathrm{P}<.001)$ was found in the $\Delta \mathrm{E}$ between tested groups after bonding to foundation blocks.

The 2-way ANOVA (Table III) revealed that regardless the ceramic thicknesses, the ceramic material used significantly influenced the $\Delta \mathrm{E}$ values $(\mathrm{P}<.001)$. 
TABLE (III) Summary of 2-way ANOVA for representation of interactions between ceramic type / thickness materials variables color representation of expirmental groups.

\begin{tabular}{|l|c|c|c|c|c|}
\hline Source & $\begin{array}{c}\text { Type III Sum of } \\
\text { Squares }\end{array}$ & df & Mean Square & F & Sig. \\
\hline Corrected Model & $44.974^{\mathrm{a}}$ & 5 & 8.995 & 19.022 & .000 \\
\hline Intercept & 169.626 & 1 & 169.626 & 358.723 & .000 \\
\hline After bonding & 35.686 & 2 & 17.843 & 37.734 & .000 \\
\hline ceramic & 4.823 & 1 & 4.823 & 10.201 & .002 \\
\hline After bonding * ceramic & 4.465 & 2 & 2.232 & 4.721 & .013 \\
\hline Error & 25.535 & 54 & .473 & & \\
\hline Total & 240.135 & 60 & & & \\
\hline Corrected Total & 70.508 & 59 & & & \\
\hline
\end{tabular}

a. $R$ Squared $=.638($ Adjusted $R$ Squared $=.604)$

b. Computed using alpha $=.05$

\section{DISCUSSION}

Color measurement and shade determination in dentistry are important tasks for the production of prosthetic materials. Shade guides was used traditionally as a color matching system, as it's an inexpensive and more practical process in spite of devices, such as spectrophotometers and colorimeters, have become popular in dental clinics as a result of their numerical expression of colors, standardization, and accuracy. ${ }^{30,35-37}$

The current study evaluated color changes of EM and ZLS in different thickness after bonding to non tooth color foundation. The null hypothesis that, the final color was not affected by the change in the type of CAD/CAM generated glass-ceramic material or the variations in ceramic thickness were rejected.

This finding was supported by the findings of Targut et al, ${ }^{33}$ who reported that, the color difference $(\triangle \mathrm{E})$ of $\mathrm{CAD} / \mathrm{CAM}$-generated lithium silicate glass-ceramic restorations is affected relative to the color of abutment tooth, ceramic thickness and cement color. Additionally, Bagis B and Turgut $\mathrm{S}^{38}$ reported that, the crystalline composition of the ceramic material determine the optical properties of the material.

Reinforcement of lithium silicate ceramics with $8-12 \%$ zirconia oxide particle decrease the color match of the material compared to IPS e.max CAD, this could be explained by relatively high refractive index of the added particles 2.20 compared with 1.5 of the glassy matrix and 1.55 of lithium disilicate particles. ${ }^{1}$

Before bonding to foundation blocks, the shade guide $\mathrm{L}^{*}$ value was found to be comparable with the ceramics used in this study. This could be related to the thickness of the middle part of the shade guide, which is thick as the ceramic specimens thickness used in this study.

The findings of this investigation showed that $\Delta \mathrm{E}$ values were affected by increase in the ceramic thickness regardless the type of CAD/CAM ceramic material used which could be related to the difference in the material optical properties. ${ }^{33}$ 
Al Ben Ali et al ${ }^{3}$ concluded that the high translucency of EM occur as a result of the optical combination of a glass matrix and the crystalline phase of lithium disilicate that decreases internal scattering of the light as it passes through the material. Subsequently, the color underlying abutment may affect the final optical properties of the restoration. As the thickness of a typical ceramic crown is approximately 1.0 $\mathrm{mm}$ at the cervical margin of the restoration and increases gradually to $2.0 \mathrm{~mm}$ close to the incisal or occlusal surfaces, ${ }^{25,27}$ the options to use a lowtranslucency (LT) CAD/CAM lithium silicateglass-ceramics may be limited with increased the amount of underlying abutment tooth discoloration. Additionally, several investigations have reported that, the abutment tooth color, translucency of the ceramic material used, and the shade of luting cement could all contribute to the resultant color e of the ceramic restorations. $3,39,40$

White opaque resin cement were used in the current study as it showed good masking ability as recommended by many researchers for bonding of glass-ceramic restorations to non tooth-colored foundation. ${ }^{41,42}$ Niu et al, ${ }^{43}$ stated that, for masking the dark color that results from bonding of lithium disilicate glass ceramic to non-tooth colored foundation, a white opaque resin cement should be used regardless its thickness.

As the thicknesses of the specimens increased, $\mathrm{L}^{*}$ values, that characterize the brightness of the specimens, reduced significantly $(\mathrm{P}<.05)$. This can be related to the increase in the absorption of incident light with thicker specimens, which reflects a minimized quantity of light and, subsequently, decrease $\mathrm{L}^{*}$ values.

After bonding to foundation block, the specimens displayed a color shift toward red, because the $a^{*}$ values decreased after cementation. All $b^{*}$ values decreased after cementation, meaning that the color shift was toward the blue end of the spectrum.
Under uncontrolled clinical satiations, clinical color matching may be estimated based upon the $\Delta \mathrm{E}$ values. The color difference is described as "perfect" when the $\Delta \mathrm{E}$ value of two colors is 0 , a value of $0.5-1.5$ units is "very good"; $1-2$ is "good"; $2-3.5$ is "clinically perceptible"; and $>3.5$ is "unacceptable." Average color differences higher than $1.0 \mathrm{\Delta E}$ are considered as visually detectable and 3.5 $\Delta \mathrm{E}$ are rated as unacceptable for clinical application. ${ }^{20,24,38}$ The results of our study indicated that both EM and ZLS CAD/CAM-generated allceramic materials were able to match the color of the shade guide however $\Delta \mathrm{E}$ value range from 2.7 to 0.7 which consider acceptable for clinical use.

The limitation of this investigation, it did not include potential variability of the shade guides. Within the same manufacturer, Shade tabs may vary between guides. These differences among the shade tabs may be interpreted as improper color measurements. This potential variation was not evaluated in this study. Additionally, only shade A1 of CAD/CAM Lithia silicate ceramic and one shade of luting cements were investigated.

\section{CONCLUSIONS}

Within the limitation of this study the following could be concluded;

1. Reinforcement of CAD/CAM Lithia silicate glass-ceramics by zirconia decreases the color production.

2. Acceptance level between the different types of ceramic materials and thickness varied. At all evaluated thicknesses before bonding to foundation blocks, EM showed the highest color matching followed by ZLS.

3. The effect of non tooth colored foundation can be overcome by increasing the thickness of fabricated crowns to enhance color match. 


\section{REFERENCES}

1. Heffernan MJ, Aquilino SA, Diaz-Arnold AM, Haselton DR, Stanford CM, Vargas MA. Relative translucency of six all-ceramic systems. Part I: core materials. J Prosthet Dent. 2002;88:4-9.

2. Conrad HJ, Seong WJ, Pesun IJ. Current ceramic materials and systems with clinical recommendations: a systematic review. J Prosthet Dent 2007; 98:389-404.

3. Al Ben Ali A, Kang K, Finkelman MD, Zandparsa R, Hirayama $\mathrm{H}$. The effect of variations in translucency and background on color differences in CAD/CAM lithium disilicate glass ceramics. J Prosthodont. 2014;23: 213-20.

4. Wiedhahn K. From blue to white: New high strength material for cerec -- IPS e.max CAD LT. Int J Comput Dent. 2007; 10:79-91.

5. Herrguth $\mathrm{M}$, Wichmann $\mathrm{M}$, Reich $\mathrm{S}$. The aesthetics of allceramic veneered and monolithic CAD/CAM crowns. J Oral Rehabil. 2005;32(10):747-52.

6. Mously HA, Finkelman M, Zandparsa R, Hirayama H. Marginal and internal adaptation of ceramic crown restorations fabricated with $\mathrm{CAD} / \mathrm{CAM}$ technology and the heat-press technique. J Prosthet Dent. 2014; 112:249-56.

7. Nogueira AD, Della Bona A. The effect of a coupling medium on color and translucency of CAD-CAM ceramics. J Dent. 2013;41:e18-23.

8. Horwitz JC. Lithium disilicate: masking discolored teeth. Dent Today. 2011;30:114, 116-7.

9. Kurbad A, Reichel K. CAD/CAM-manufactured restorations made of lithium disilicate glass ceramics. Int J Comput Dent. 2005;8:337-48.

10. Chaiyabutr Y, Kois JC, LeBeau D, Nunokawa G. Effects of abutment color, cement color, and ceramic thickness on the resulting optical color of a CAD/ CAM glass-ceramic lithium disilicatereinforced crown. J Prosthet Dent 2011; 105:83-90.

11. Niu E, Agustin M, Douglas RD. Color match of machinable lithium disilicate ceramics: effects of foundation restoration. J Prosthet Dent. 2013;110:501-9.

12. Volpato CA, Monteiro S Jr, de Andrada MC, Fredel MC, Petter CO. Optical influence of the type of illuminant, substrates and thickness of ceramic materials. Dent Mater. 2009;25:87-93.
13. Shimada K, Nakazawa M, Kakehashi Y, Matsumura H. Influence of abutment materials on the resultant color of heat-pressed lithium disilicate ceramics. Dent Mater J. 2006; 25:20-5.

14. Dozíc A, Kleverlaan CJ, Meegdes M, vander Zel J, Feilzer AJ. The influence of porcelain layer thickness on the final shade of ceramic restorations. J Prosthet Dent 2003; 90:563-570.

15. Chang J, Da Silva J, Sakai M, Kristiansen J, Nagai SI. The optical effect of composite luting cement on all ceramic crowns. J Dent 2009; 37:937-43.

16. De Azevedo Cubas GB, Camacho GB, Demarco FF, PereiraCenci $\mathrm{T}$. The effect of luting agents and ceramic thickness on the color variation of different ceramic against a chromatic background. Eur J Dent 2011: 245-52.

17. Reich S, Hornberger $\mathrm{H}$. The effect of multicolored machinable ceramics on the esthetics of all-ceramic crowns. J Prosthet Dent. 2002 Jul;88(1):44-9.

18. Barão VA, Gennari-Filho H, Goiato MC, dos Santos DM, Pesqueira AA. Factors to achieve aesthetics in all-ceramic restorations. J Craniofac Surg. 2010;21:2007-12. Review.

19. Ghulman MA, Awad MA. Color variation between matched and fabricated shades of different ceramics. J Prosthodont. 2013; 22:472-7.

20. Knispel G. Factors affecting the process of color matching restorative materials to natural teeth. Quintessence Int $1991 ; 22: 525-31$.

21. Denissen H, Dozic A, van Waas M, Feilzer A. Effects of 5 manipulative variables on the color of ceramics used for computer generated restorations. Quintessence Int 2007; 38:401-8.

22. Vichi A, Ferrari M, Davidson CL. Influence of ceramic and cement thickness on the masking of various types of opaque posts. J Prosthet Dent 2000;83:412-7.

23. Stevenson B, Ibbetson R. The effect of the substructure on the color of samples/restorations veneered with ceramic. J Dent 2010;38:361-8.

24. Nakamura T, Saito O, Fuyikawa J, Ishigaki S. Influence of abutment substrate and ceramic thickness on the color of heatpresses ceramic crowns. J Oral Rehabil 2002; 29:805-9.

25. Azer SS, Ayash GM, Johnston WM, Khalil MF, Rosenstiel SF. Effect of esthetic core shades on the final color of IPS Empress all-ceramic crowns. J Prosthet Dent 2006; 96:397-401. 
26. Stevenson B, Ibbetson R. The effect of the substructure on the color of samples/restorations veneered with ceramic: a literature review. J Dent 2010; 38:361-8.

27. Öngül D, Şermet B, Balkaya MC. Visual and instrumental evaluation of color match ability of 2 shade guides on a ceramic system. J Prosthet Dent 2012; 108:9-14.

28. Alqahtani MQ, Aljurais RM, Alshaafi MM. The effects of different shades of resin luting cement on the color of ceramic veneers. Dent Mater J 2012;31:354-61.

29. Douglas RD, Steinhauer TJ, Wee AG. Intraoral determination of the tolerance of dentists for perceptibility and acceptability of shade mismatch. J Prosthet Dent 2007; 97:200-8

30. Douglas RD, Przybylska M. Predicting porcelain thickness required for dental shade matches. J Prosthet Dent 1999;82: 143-9.

31. Lund PS, Piotrowski TJ. Color changes of porcelain surface colorants resulting from firing. Int J Prosthodont 1992;5:22-7.

32. Barizon KT, Bergeron C, Vargas MA, Qian F, Cobb DS, Gratton DG, Geraldeli S. Ceramic materials for porcelain veneers: part II. Effect of material, shade, and thickness on translucency. J Prosthet Dent. 2014;112:864-70.

33. Turgut S, Bagis B, Ayaz EA. Achieving the desired colour in discoloured teeth, using leucite-based CAD-CAM laminate systems. J Dent. 2014;42: 68-74.

34. Çömlekoğlu ME, Paken G, Tan F, Dündar-Çömlekoğlu M, Özcan M, Akan E, Aladağ A.Evaluation of Different Thickness, Die Color, and Resin Cement Shade for Veneers of Multilayered CAD/CAM Blocks. J Prosthodont. 2015 Oct 26.
35. Paul S, Peter A, Pietrobon N, Hammerle CHF. Visual and spectrophotometric shade analysis of human teeth. Journal of Dental Research 2002;81:578-82. 37. Corciolani G, Vichi A, Louca C, Ferrari M. Color match of two different ceramic systems to selected shades of one shade guide. $\mathrm{J}$ Prosthet Dent. 2011;105:171-6.

36. Barath VS, Faber FJ, Westland S, Niedermeier W. Spectrophotometric analysis of all-ceramic materials and their interaction with luting agents and different backgrounds. Adv Dent Res 2003;17: 55-60

37. Fasbinder DJ. Digital dentistry: innovation for restorative treatment. Compend Contin Educ Dent 2010; 31:2-11.

38. Bagis B, Turgut S. Optical properties of current ceramics systems for laminate veneers. J Dent. 2013 Aug;41 Suppl $3: \mathrm{e} 24-30$

39. Dozic A, Kleverlaan CJ, Meegdes M, van der Zel J, Feilzer AJ. The influence of porcelain layer thickness on the final shade of ceramic restorations. Journal of Prosthetic Dentistry 2003;90:563-70. 9.

40. Turgut S, Bagis B, Ayaz EA. Achieving the desired colour in discoloured teeth, using leucite-based CAD-CAM laminate systems. J Dent 2014;42:68-74.

41. Trushkowsky RD. Esthetic and functional consideration in restoring endodontically treated teeth. Dent Clin North Am 2011;55: 403-10.

42. Dozic A, Tsagkari M, Khashayar G, Aboushelib M. Color management of porcelain veneers: influence of dentin and resin cement colors. Quintessence Int 2010;41:567-73.

43. Niu E, Agustin M, Douglas RD. Color match of machinable lithium disilicate ceramics: Effects of cement color and thickness. J Prosthet Dent. 2014;111:42-50. 